\title{
Sick Euthyroid Syndrome
}

National Cancer Institute

\section{Source}

National Cancer Institute. Sick Euthyroid Syndrome. NCI Thesaurus. Code C113170.

Abnormal thyroid function tests, low triiodothyronine with elevated reverse

triiodothyronine, in the setting of non-thyroidal illness. 